\title{
Rancang Bangun Sistem Informasi Perlengkapan Laboratorium Komputer Berbasis Web
}

\author{
Asep Saifudin ${ }^{1}$, Gustina ${ }^{2}$ \\ ${ }^{1}$ Program Studi Teknik Informatika, ${ }^{2}$ Program Studi Manajemen Informatika \\ ${ }^{1,2}$ STTIKOM Insan Unggul Cilegon \\ Email : *1asep.saifudin22@gmail.com, ${ }^{2}$ gustina0881@ gmail.com
}

\begin{abstract}
Abstrak
Perlengkapan Laboratorium Komputer yang berjalan pada PPM Al Hasyimiyah Kota Cilegon menggunakan manual dimulai catat barang dan barang masuk, mencatat persediaan barang keluar, pengecekan barang, sampai menghasilkan laporan stok barang. Untuk membantu masalah ini maka dibutuhkan suatu sistem informasi persediaan perlengkapan laboratorium komputer metode analisa swot, software sublime text, uml menggunakan visual paradigm, mysql sebagai database nya yang akan memudahkan admin dalam mencatat data barang, persediaan barang masuk, persediaan barang keluar, pengecekan barang dan membuat laporan.
\end{abstract}

Kata Kunci: sistem informasi, persediaan, perlengkapan, web

\begin{abstract}
Computer Laboratory Equipment that runs on PPM Al Hasyimiyah Cilegon City uses manual starting from recording incoming goods and goods, recording outgoing goods inventory, checking goods, to producing inventory reports. To help with this problem, a computer laboratory equipment inventory information system is needed, the SWOT analysis method, sublime text software, uml using the visual paradigm, MySQL as a database which will make it easier for the admin to record goods data, incoming goods inventory, outgoing goods inventory, checking goods and make a report.
\end{abstract}

Keywords: information systems, supplies, equipment, web

\section{PENDAHULUAN}

Permasalahan yang sedang dihadapi oleh PPM Al-Hasyimiah Kota Cilegon adalah proses persediaan perlengkapan pada laboratorium Komputer. Pada proses persediaan tersebut mengalami kesulitan dikarena pada penginputan data masih menggunakan buku besar atau manual. Dalam penulisan pendataan laboratorium, pada data tersebut hanya terdapat nama alat, jumlah serta kondisi baik atau rusak, sehingga data yang diperoleh masih kurang akurat. Admin laboratorium Komputer melakukan pengecekan kembali secara berkala dalam waktu sebulan sekali tetapi tidak ada perubahan data pada pembukuan jika perlengkapan laboratorium Komputer mengalami kerusakan dan hilang, sehingga pada data pembukuan tersebut tidak akurat. Sedangkan pada pendataan keseluruhan persediaan perlengkapan laboratorium Komputer dilakukan persemester sekali. Sehingga kerusakan pada perlengkapan laboratorium tidak terkontrol secara baik. Melihat permasalahan yang terjadi, maka dibuatkanlah sebuah sistem yang berbasis web yang sudah memiliki database dalam mengetahui persediaan perlengkapan laboratorium Komputer sehingga admin dapat langsung mengubah ketika terjadi kerusakan, kehilangan, serta pemasukan dan pengeluaran. 


\section{Tinjauan Pustaka}

\section{laboratorium}

Menurut Indrwan, dkk (2020:23), berpendapat bahwa Laboratorium adalah tempat yang digunakan untuk melakukan berbagai percobaan atau penelitian yang berkaitan dengan fisika, biologi dan kimia atau bidang ilmu pengetahuan lainnya, yaitu ruangan tertutup atau ruang terbuka seperti taman dan lain-lain.[1]

\section{Komputer}

Menurut Fachri, dkk (2020:13), berpendapat bahwa Komputer adalah mesin hitung elektronik yang dengan cepat menerima informasi masukan digital dan memproses informasi tersebut sesuai dengan serangkaian instruksi yang disimpan di komputer dan menghasilkan keluaran informasi yang dihasilkan setelah diproses.[2]

\section{Analisa SWOT}

Sari dkk (2020:109 ), Analisis SWOT adalah evalausi menyeluruh atas kekuatan, kelemahan, peluang, dan ancaman yang dimiliki dan dihadapi oleh perusahaan. Jika analisa kekeuatan dan kelemahan adalah analisa terhadap kondisi internal perusahaan, maka peluang dan ancaman merupakan analisis kondisi eksternal perusahaan.[3]

\section{LITERATUR REVIEW}

Beberapa hasil penelitian sebelumnya sejalan dengan penelitian ini, antara lain :

1) Khalim dkk (2020)[4] dalam penelitiannya Aplikasi Inventaris Barang Berbasis Web Pada Laboratorium Komputer Fastikom, hasil dari penelitian sistem yang dibuat dapat memudahkan admin dalam memantau barang yang masuk dan keluar serta pembuatan laporan rekapitulasi data.

2) Lediwara dan Rivaldi (2019)[5] dalam penelitiannya Perancangan Sistem Informasi Inventaris Barang Laboratorium Komputer SMPN 11 Kota Bengkulu, hasil dari penelitian istem yang dibuat maka dapat mempermudah dan mengurangi resiko kesalahan dalam pengelolaan data persediaan barang laboratorium komputer dan mempermudah pekerjaan dalam proses transaksi peminjaman barang.

3) Maharani dan Wiyono (2016)[6] dalam penelitiannya Sistem Informasi Inventaris Laboratorium Berbasis Web Pada Stikes Bhakti Mandala Husada Slawi, hasil dari penelitian ini sistem dapat membantu mengintegrasikan data dan mengefektifkan penyimpanan data.

\section{METODE PENELITIAN}

Metode yang digunakan dalam penelitian ini menggunakan analissis SWOT, yang merupakan teknik perancangan strategi yang berguna untuk melihat kondisi perusahaan baik internal maupun eksternal yang nantinya akan digunakan sebagai indikator untuk mengetahui kekuatan, kelemahan, peluang dan ancaman sehingga dapat membantu perusahaan dalam pengambilan keputusan.

\section{HASIL DAN PEMBAHASAN}


Use Case Diagram

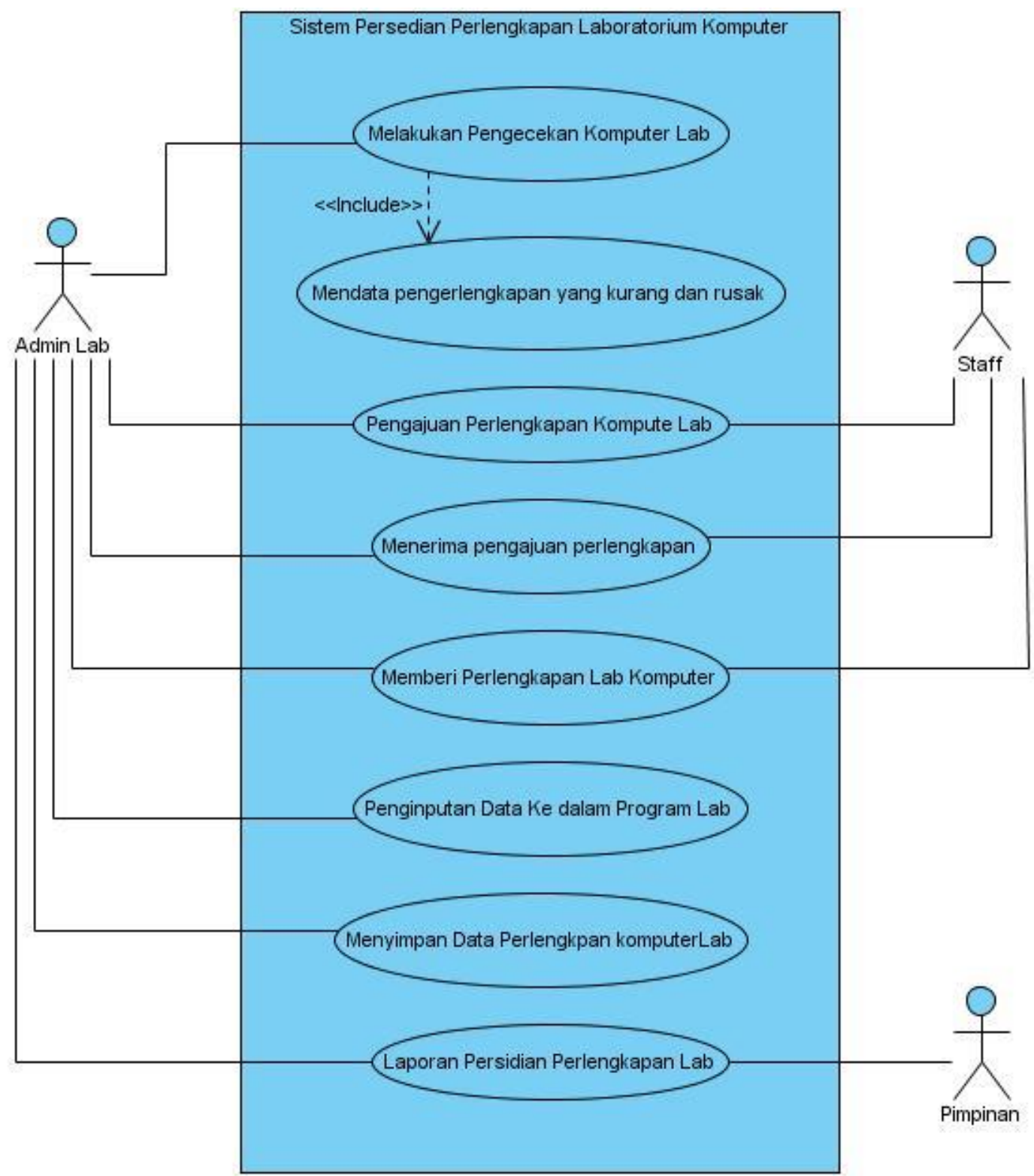

Gambar 1. Use Case Diagram

Gambar diatas berisi:

Admin lab melakukan pengecekan terhadap komputer lab untuk mendata perlengkapan yang kurang dan kurang terhadap komputer, dirasa ada masalah pada komputer admin mengajukan perlengkapan computer pada staff. Setelah perlengkapan computer diterima oleh maka tugas admin untuk menginput segala keperluan yang akan dimasukkan kedalam program yang ada pada komputer lab sampai terselesaikan semua, kemudian admin melaporkan persediaan perlengkapan lab pada pimpinan.

\section{Sequence diagram}




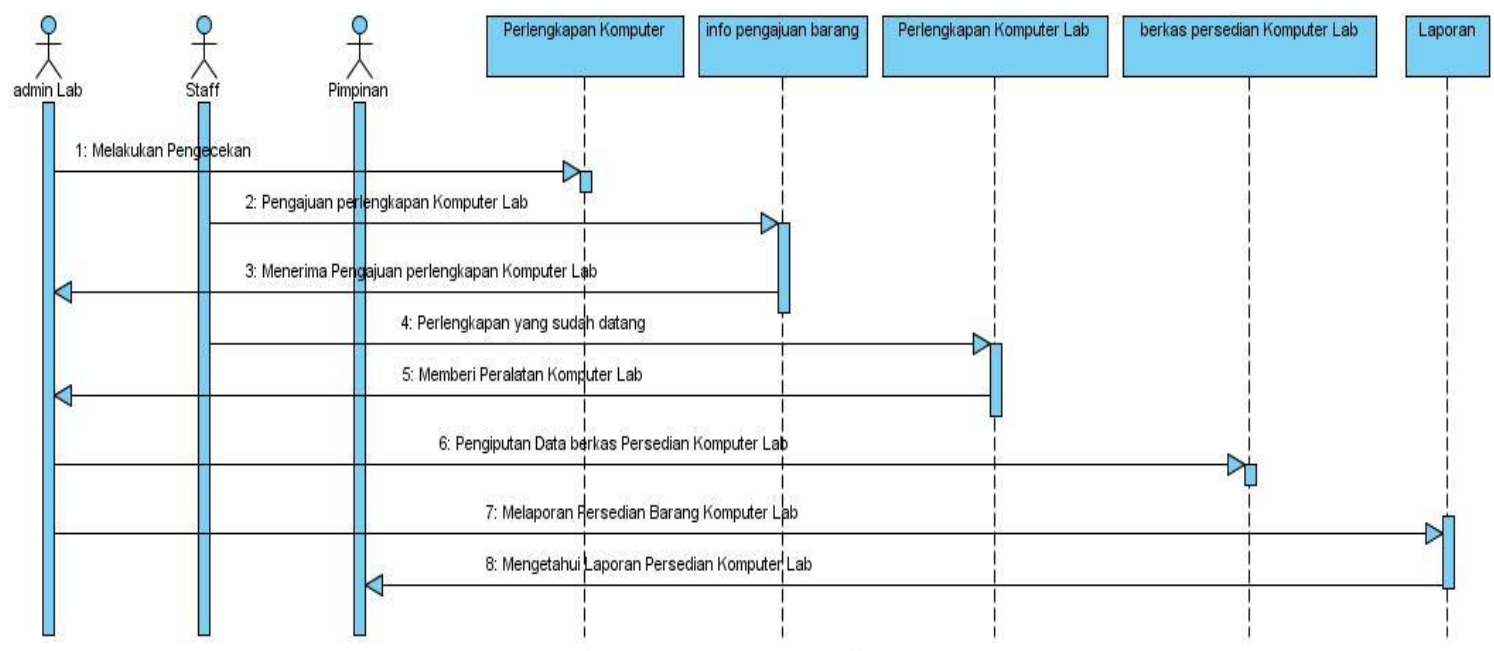

Gambar 2. Sequence diagram

Gambar diatas berisikan :

Tiga actor terdiri dari: admin lab, staff, dan pimpinan; lima Lifelines terdiri dari: perlengkapan computer, info pengajuan barang, perlengkapan komputer lab, berkas persediaan komputer lab, dan laporan; delapan Message dalam memberikan informasi terkait gambaran tentang kegiatan yang sedang berlangsung yang dilakukan oleh aktor.

\section{Class Diagram sistem diusulkan}
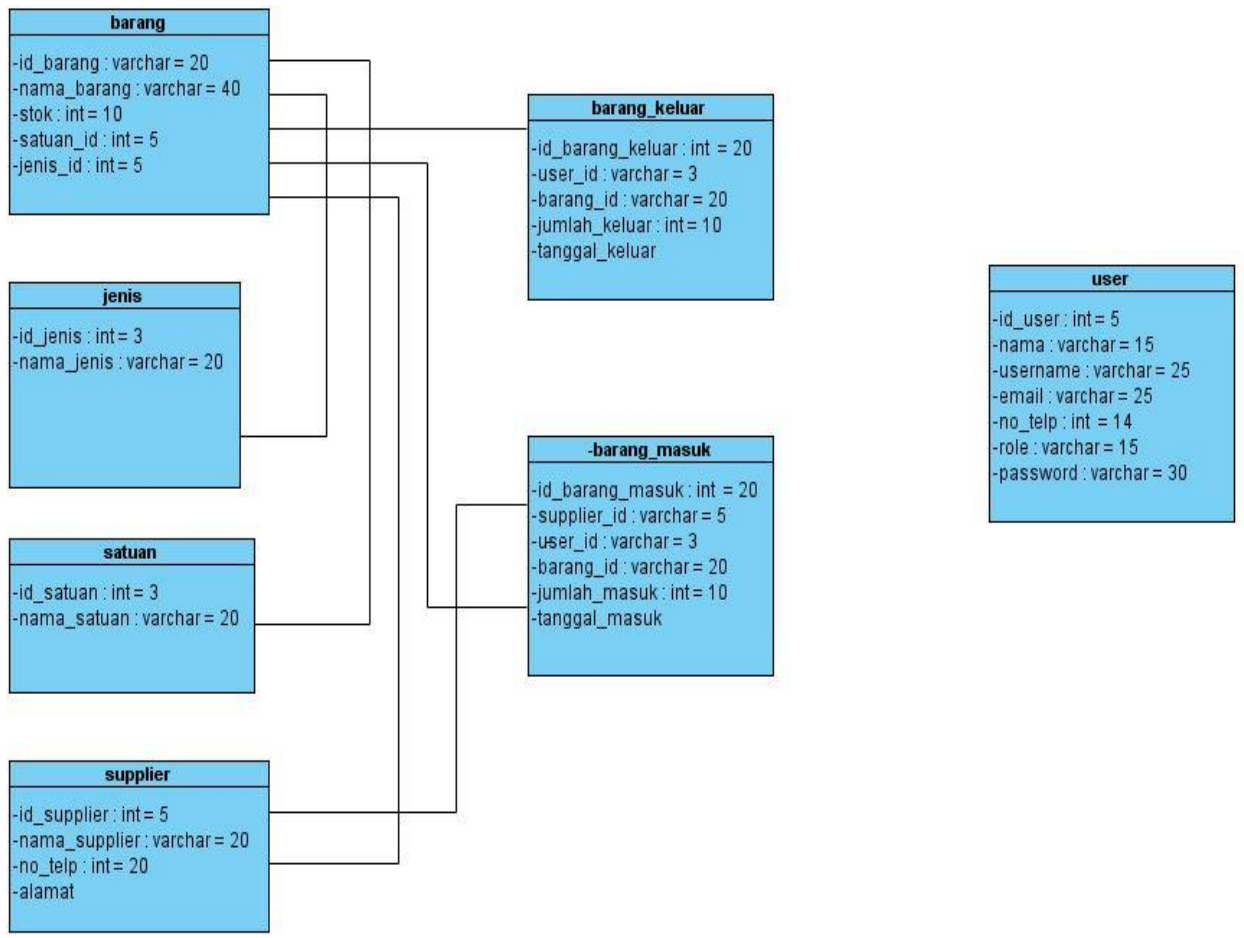

Gambar 3. Class Diagram

Gambar diatas membahas tentang perancangan database yang menjelaskan tentang tabel-tabel database, spesifikasi database yang akan digunakan pada sistem yang dibangun.

\section{Desain Menu Login}




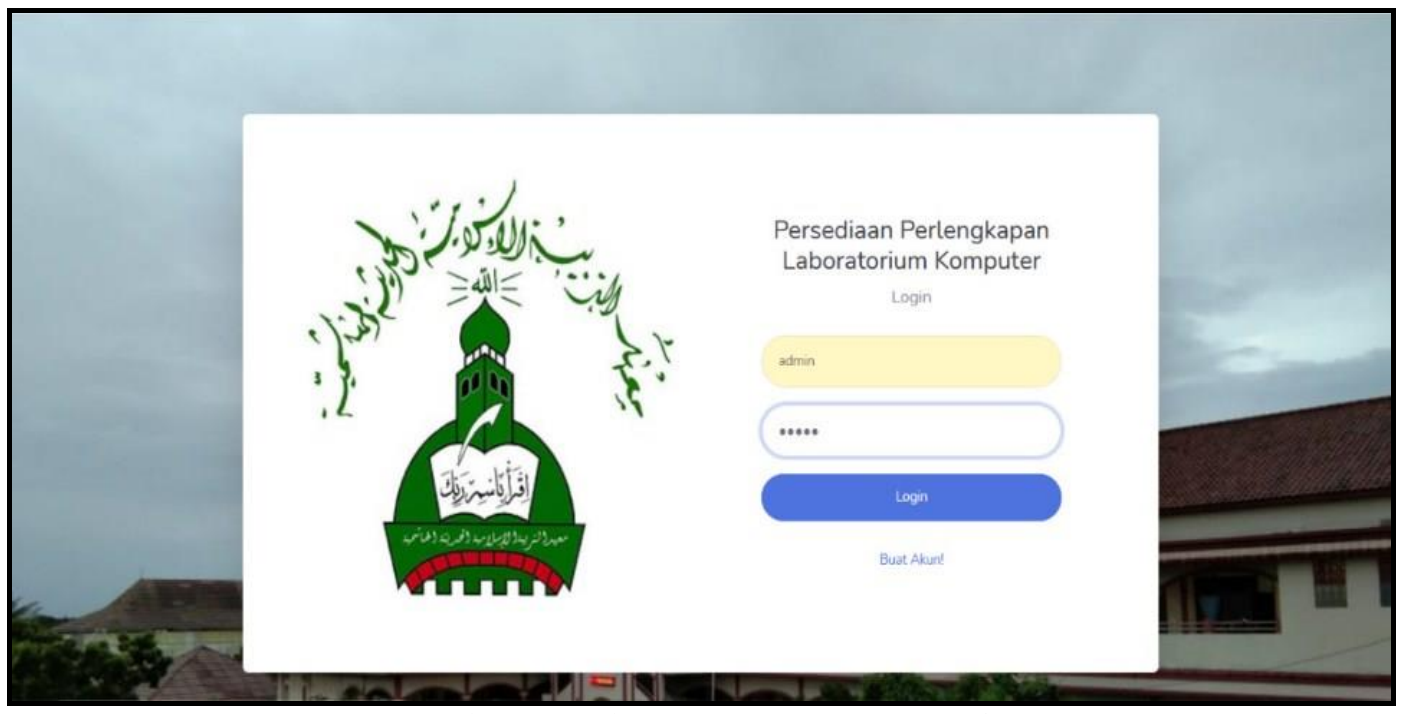

Gambar 4. Halaman Menu Utama Login

Halaman login merupakan tampilan menu yang pertama kali akan tampil ketika user menjalankan system ini. Padahal aman ini user diminta untuk memasukkan user name, password, dan hak akses sebagai apa, agar dapat mengakses halaman utama. Didalam system ini hanya meliki hak akses yaitu Persediaan Perlengkapan Laboratorium Komputer

\section{Desain Halaman Dashboard Persediaan Perlengkapan Lab}

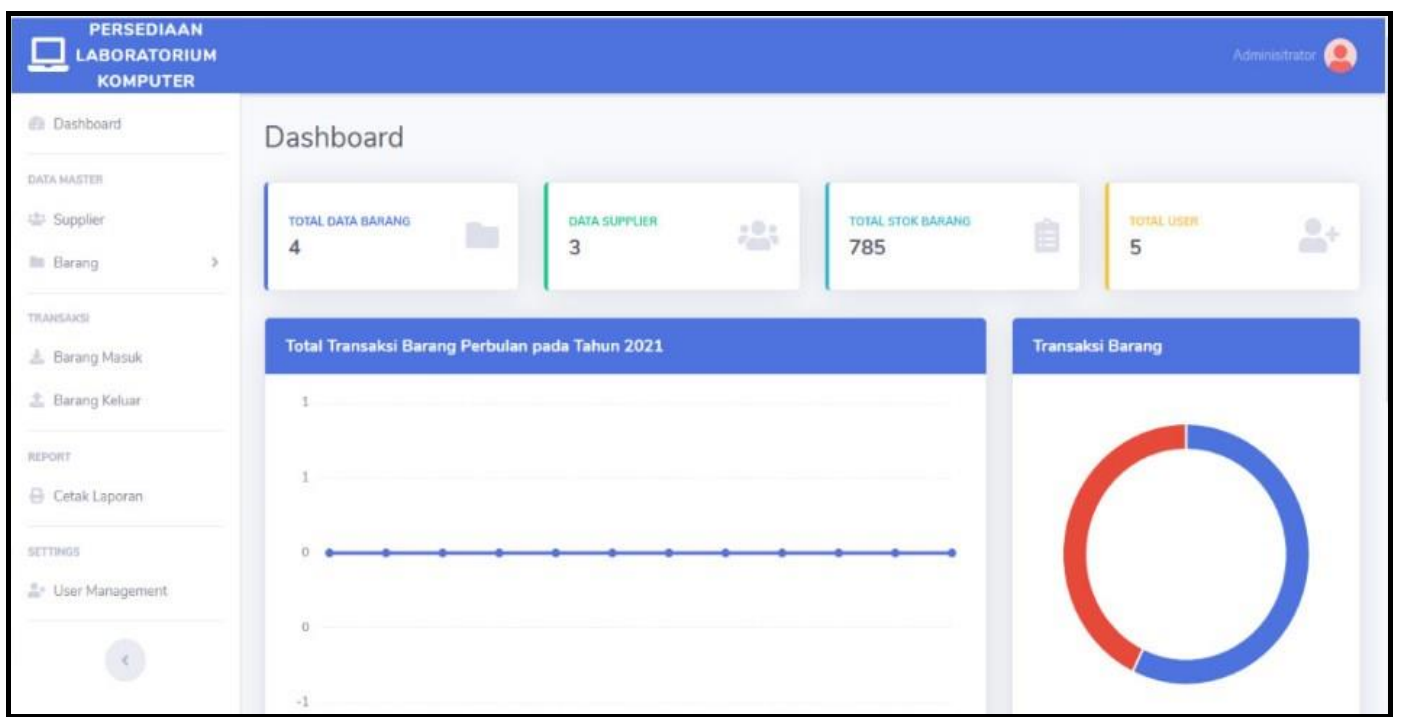

Gambar 5. Tampilan Dashboard

Halaman Dashboard Perlengkapan Lab merupakan tampilan menu utama setelah Admin Lab melakukan login pada menu login

\section{Desain Supplier}




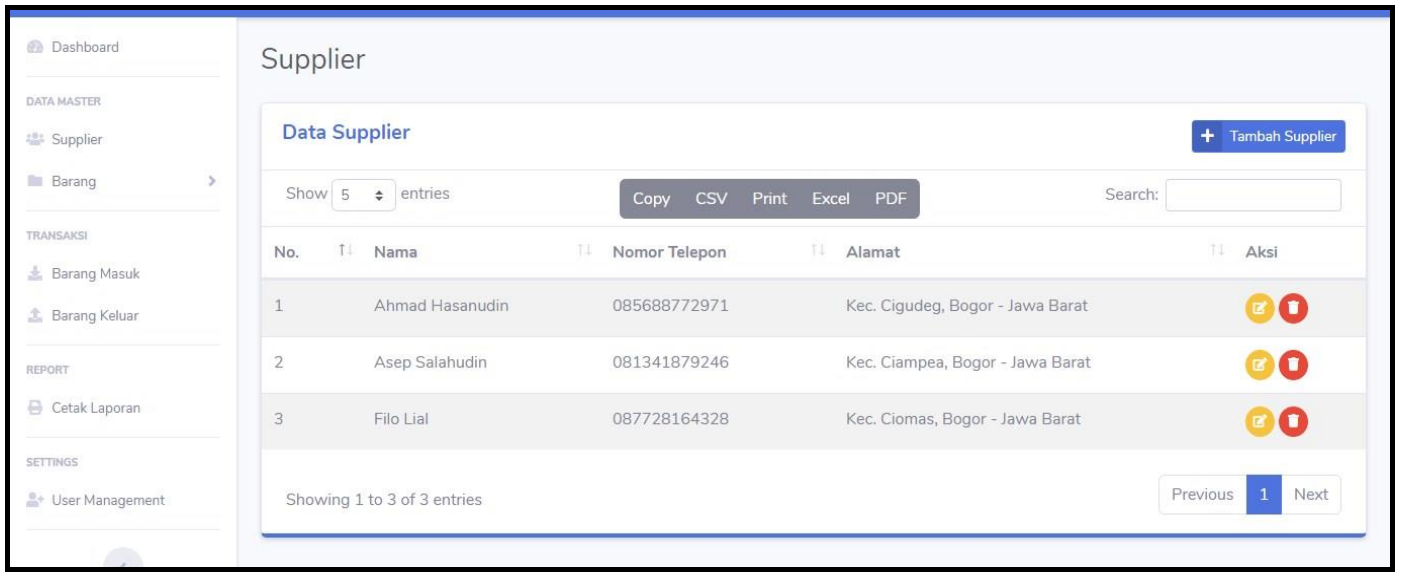

Gambar 6. Tampilan Tabel Barang

Halaman Supplier merupakan tampilan yang berisikan barang yang mau ditambah kepersediaan Perlengkapan Komputer Lab

\section{Desain Barang Masuk}

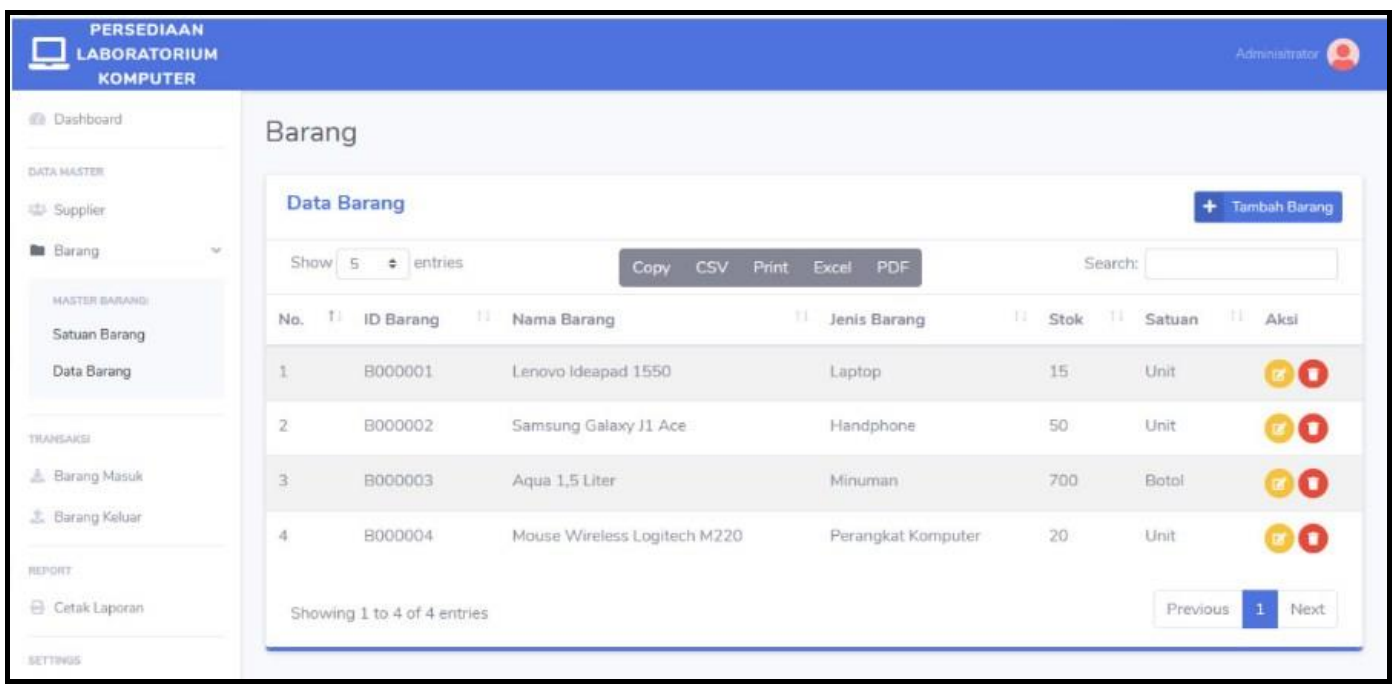

Gambar 7. Tampilan Tabel User

Halaman Tabel User merupakan tampilan yang berisikan barang yang mau ditambah kepersediaan Perlengkapan Komputer Lab.

\section{Desain Barang keluar}




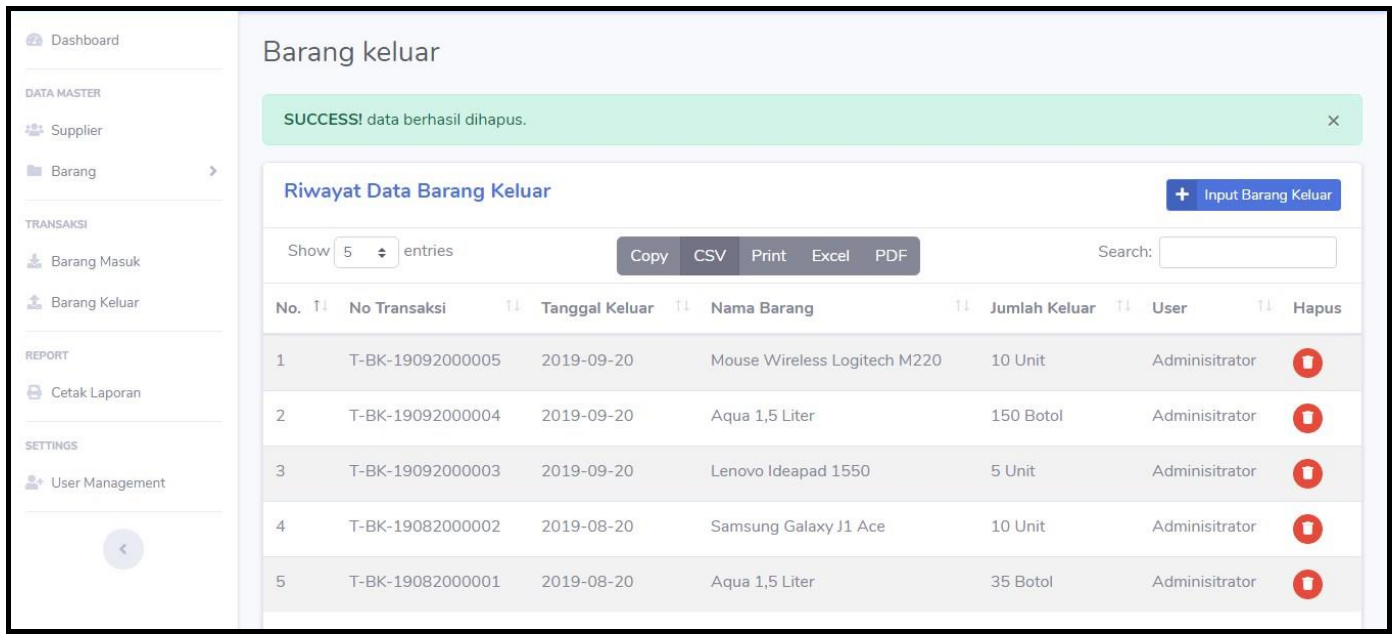

Gambar 8. Tampilan Tabel Supplier

HalamanTabel Supplier untuk menambahkan barang keluar pada aplikasi Persedian baarang Perlengkapan Komputer.

\section{Desain Laporan Pengadaan Transaksi}

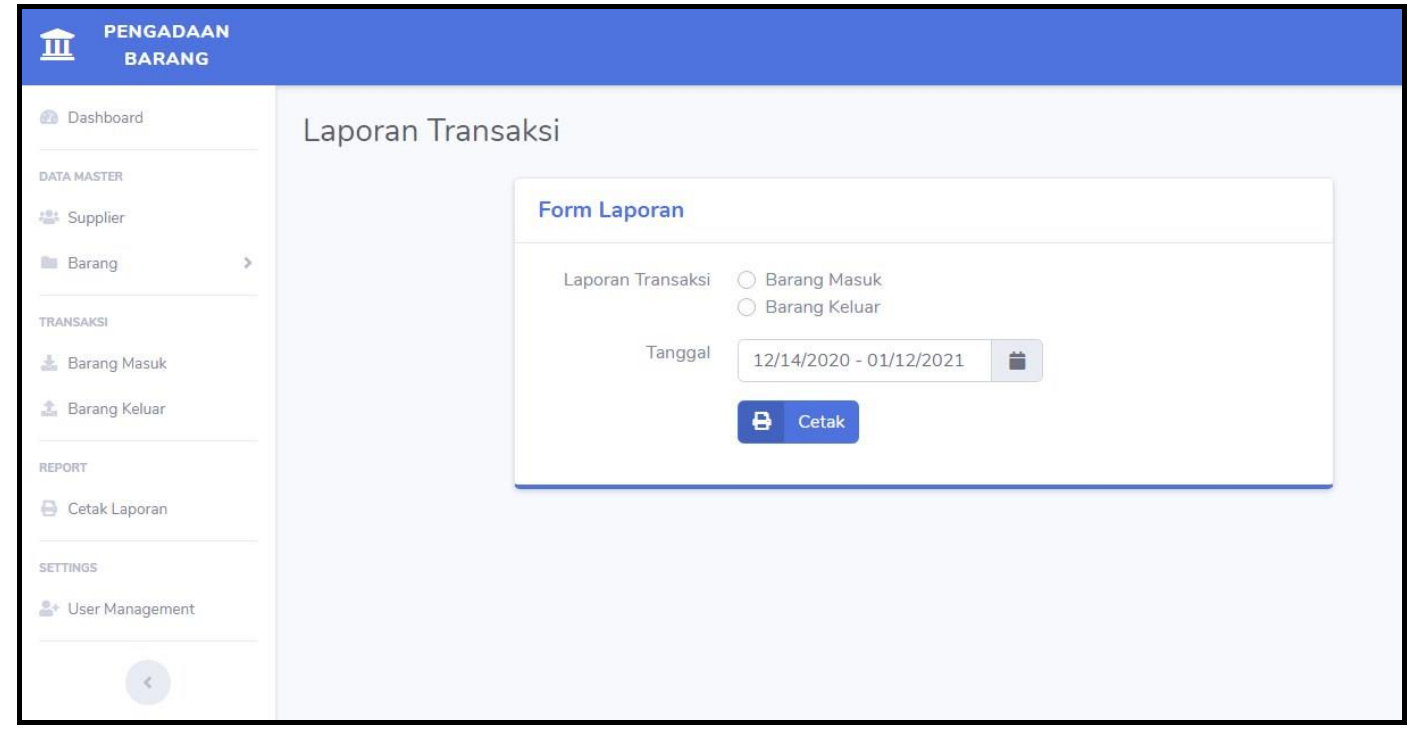

Gambar 9. Tampilan Laporan Transaksi

Halaman Laporan Transaksi melihat laporan yang sudah di input barang masuk dan barang keluar

\section{KESIMPULAN}

Dalam pengolahan persediaan perlengkapan laboratorium komputer masih menggunakan sistem manual sehingga perusahaan mengalami beberapa kendala dalam pencatatan data persediaan barang masuk serta keluar dan pembuatan la[oran stok barang, sehingga menyebabkan beberapa maslaha dianataranya informasi tidak akurat karena terdapat perbedaan data jumlah stok barang antara data yang dibuat dengan barng fisiknya. dalam pembuatan laporan pun membutuhkan waktu yang cukup lama dalam penyajian laporan. Oleh karena itu, diperlukan sistem yang dapat memudahkan admin dalam menangani persdiaan perlengkapan laboratorium komputer. 


\section{SARAN}

Dengan sistem komputerisasi ini admin dituntut untuk menjaga sistem agar sistem tidak mudah rusak dan awet, serta dilakukan pelatihan bagi admin. kemudian setelah sistem ini diimplementasikan dengan baik, dimungkinkan untuk melakukan pengembangan sistem baru, untuk melengkapi kekurangan-kekurangan yang ada pada sistem saat ini. Serta dapat ditingkatkan atau ditambah fungsi lain agar dapat sejalan dengan perkembangan ilmu teknologi dan informasi.

\section{DAFTAR PUSTAKA}

[1] Indrawan, I., dkk. 2020. Manajemen Laboratorium Pendidikan. Pasuruan : CV Penerbit Qiara Media

[2] Fachri, B., dkk. 2020. Arsitektur dan Organisasi Komputer. Medan : Yayasan kita menulis

[3] Sari, A, P., dkk. 2020. Kewirausahaan dan Bisnis Online. Medan : Yayasan Kita Menulis

[4] Khalim, A.A., dkk. 2020. Aplikasi Inventaris Barang Berbasis Web Pada Laboratorium Komputer Fastikom. Device, 10(2), 44-50.

[5] Lediwara, N., \& Rivaldi, M. 2019. Perancangan Sistem Informasi Inventaris Barang Laboratorium Komputer SMPN 11 Kota Bengkulu. Jurnal Teknologi Sistem Informasi dan Aplikasi, 2(4), 117-129

[6] Maharani, A.D., \& Wiyono, S. 2016. Sistem Informasi Inventaris Laboratorium Berbasis Web Pada STIKES Bhakti Mandala Husada Slawi. Jurnal Informatika, 1(1), 7-10 